\title{
Factors Impeding Knowledge Sharing, Knowledge Creation and Knowledge Use among English Language Teachers: An Evidence from Pakistani Educational Organizations
}

\author{
Muhammad Younas, Khadija Akram, Asim Shahzad,Fazeela Zainab \\ Assistant Professor, Dept. of English, University of Central Punjab, Lahore ( Sargodha Campus) Candidate for \\ M.Phil in Applied Linguistics \\ Candidate for M.Phil in English Literature Lahore Leads University, Lahore \\ Candidate for M.Phil in Applied Linguistics Lahore Leads University, Lahore \\ Candidate for M.Phil in Applied Linguistics Lahore Leads University, Lahore
}

\begin{abstract}
This paper aims at discovering the problems faced by English Language Teachers in knowledge sharing, knowledge creation and knowledge use. The factors like large-size classes, lack of resources, prescriptive curriculum, unmotivated students and the faulty assessment system create impediments for English language teachers in knowledge use whereas the factors like centralized organizational structure, excess of work, lack of trust, lack of motivation and an absence of knowledge sharing and knowledge receiving behavior among English teachers are hurdles in knowledge sharing and knowledge creation. Data were collected through randomly selected sample of 150 in-service teachers of English. Data were simply elaborated through charts by the researchers. Finally on the basis of findings, certain generalizations are made in relation to the factors that hamper the process of knowledge sharing, knowledge creation and knowledge use. There are also given some recommendations that may be valuable for the betterment of the process of knowledge sharing, knowledge creation and knowledge use in educational organizations.
\end{abstract}

Keywords: Knowledge sharing, Knowledge creation and Knowledge use

\section{Introduction}

It is an era of competition and the educational organizations need handling explicit and tacit knowledge of their employees effectively to sustain their academic excellence .Block, D. \& Cameron, D. (2002) opine that knowledge management shows a concern for considering the fact that knowledge possessed by individuals is a valuable asset. They are of the view that the knowledge is an intellectual asset and it must be developed and transferred to others. Liss (1999,p.1) defines that " knowledge management is a formal, directed process of determining what a company has that could benefit others in the company and then devising ways to making it easily available." Bonner, (2000b) explains that there are few organizations that use the explicit and tacit knowledge of their employees effectively. Sternberg, (1997) defines tacit knowledge as a highly personal and objective form of knowledge that can be only inferred from the discussion of others. Hansen et al. (1999) describe that explicit knowledge is academic data that is described in formal language. Explicit knowledge needs an academic understanding that is achieved through formal education. Knowledge sharing and knowledge creation are interlinked. Knowledge sharing and its implementation provide solutions of many problems faced by organizations. This process is called knowledge creation. The process of knowledge sharing, knowledge creation and knowledge use is obstructed at the individual level and at the organizational level at the same time .This research exposes the factors that are hindrances in knowledge sharing, knowledge creation and knowledge use .The specific targets of this study are as under:

1. To expose the factors that hamper the process of knowledge sharing and knowledge creation among the teachers of English in educational organizations

2. To point out the obstacles faced by the teachers of English in knowledge use

3. To bring the knowledge management practices and methods into educational organizations

Knowledge Use

\section{Literature Review And Hypotheses}

Siddiqui, S. (2007) opines that the assessment system deeply influences the educational set-up of Pakistan. It does not allow the teachers to utilize their potential for using their knowledge. It is also concluded that nothing has been done to improve this system. Burgess et al, (2002) and Fisher, R. (2004) conclude that prescriptive curriculum and tightly defined assessment system damage teachers' professional autonomy and creativity. Teachers are no independent in their teaching so they cannot use knowledge independently. They 
have to seek permission from higher authorities at every step. Hanke, V. (2002) believes that if the curriculum and assessment system are not flexible for the teachers, the natural potential for use of knowledge will be constrained. Scholte J.A. (2001) demonstrates that the teachers must enhance the competitive abilities of their students by using number of technologies. In this way the learning of students can be made better. It becomes necessary to have well equipped classroom for using technologies. Less equipped classrooms cannot provide an environment in which the teachers can use their knowledge with ease. Here in Pakistan, lack of resources is an obstacle in making classrooms well-equipped. Crystal D. (2001) suggests that the teacher should adjust their curriculum plans to meet the demands of society. But the situation in Pakistan is quite pathetic as for as the curriculum is concerned. The prescriptive curriculum does not allow the teachers to use their knowledge independently. The teachers are always bound to follow this well- defined curriculum. So, this situation is a hurdle for teachers to use their knowledge in classrooms. Heller, M. (2005) agrees that the decentralization and deregulation of English curricula makes the schools and teachers more autonomous in using knowledge. But in Pakistan, nothing has been done to change the curricula so the teachers are unable to use their knowledge freely. Smith, L.(2008) says that the institutions are becoming autonomous in developing curriculum. In this way, teachers are free to teach whatever they want according to the taste of students. But in Pakistan, teachers are still bound to teach according to prescriptive curriculum. It hampers the teachers to use their knowledge. Al-Otaibi (2004) is of the view that motivated learners can pay high cost and even make sacrifices to achieve their goals in learning foreign language. It was also found that motivated learners can learn language more effectively. The assumption can be made that de-motivated students themselves are a great hurdle for teachers in using knowledge.

\section{Knowledge Sharing and Knowledge Creation}

Leonard-Barton (1995) gives his opinion that an organization is both the storage of knowledge and creator of knowledge at the same time. Storage of knowledge is in form of employees replete with unique skills and expertise and some formal knowledge in the explicit form. Knowledge creation starts after knowledge sharing. Shared knowledge of employees puts forward solutions to problems faced by an organization. Problem solving is one of major knowledge creating activities. The positive role of an organization is very important in the effective process of knowledge sharing and knowledge creation process. Nonaka \& Takeuchi (1997) are of the view in their knowledge conversion model that knowledge creation happens when there is the interaction between explicit and tacit knowledge. Knowledge conversion activities include externalization, internalization, combination and socialization. Nonaka \& Takeuchi (1995) also explain in their SECI model that tacit knowledge gets converted into tacit knowledge by sharing experiences. Tsai and Ghoshal (1998) demonstrate that the interaction built through socialization among the employees of the organizations facilitates the knowledge sharing activities. So it can be concluded that the absence of socialization in the organization hinders the knowledge sharing and knowledge creation process. Lin (2008) explains that knowledge sharing behavior of employees in organizations very is very important in order to transfer the knowledge of an individual to many individuals to make the organizations successful. Jiacheng et al (2012) agree that knowledge sharing behavior among employees creates cooperation for mapping out the fortunes of the organization. Szulanski (1996) suggests that some individuals are unwilling to share their knowledge because they feel that it will bring others to their level and their promotions will be disturbed. Abrams et al. (2003 p.65) point out that " trust leads to increase overall knowledge exchange, makes knowledge exchanges less costly, and increases the likelihood that knowledge acquired from a colleague is sufficiently understood and absorbed that a person can put it to use." Tsai (2002) gives his view that decentralized structure of the organization promotes communication and causes increase in employees' motivation and satisfaction. Damanpour (1999) considers decentralized structure of the organization facilitative to the success of knowledge management activities and methods.

\section{This study will test the following hypotheses:}

H.1. Less equipped classrooms due to lack of resources, unmotivated students and faulty assessment system hinder the process of knowledge use.

H. 2. Large-size classes and prescriptive curriculum obstruct the process of knowledge use.

H. 3. Lack of motivation and lack of trust among English language teachers impede knowledge sharing and knowledge creation.

H. 4. Absence of socialization due to excess of work and centralized structure of the organization are obstacles in knowledge sharing and knowledge creation.

H. 5. Lack of knowledge sharing and knowledge receiving behavior among English teachers is also a barrier in knowledge sharing and knowledge creation. 


\section{Methodology}

The population of this study was 150 in-service teachers of English irrespective of gender, level, age and sector. Teachers of English were selected for collecting data because English is taught as a compulsory subject and the teachers of English are involved in almost all the programs. The study was quantitative in nature. Data were collected through questionnaire using random sampling method. The questionnaire used a five point Likert scale. Ten variables: large-size classes, lack of resources, prescriptive curriculum, unmotivated students, the faulty assessment system, centralized organizational structure, excess of work, lack of trust, lack of motivation and an absence of knowledge sharing and knowledge receiving behavior were addressed in this study. There were twenty items in questionnaire and two questions on each variable were to be answered by each respondent. Keeping in mind the research ethics, the questionnaire was given for filling to those who showed their willingness.140 out of $150(93.33 \%)$ questionnaires were received. 7 questionnaires were incomplete enough not to be interpreted. Among remaining 133 questionnaires, 53 questionnaires $(39.84 \%)$ were filled in by the female teachers and 80 questionnaires $(60.16 \%)$ by the male teachers. Data interpretation has been done through bar charts.

4.1

IV. Results And Discussions

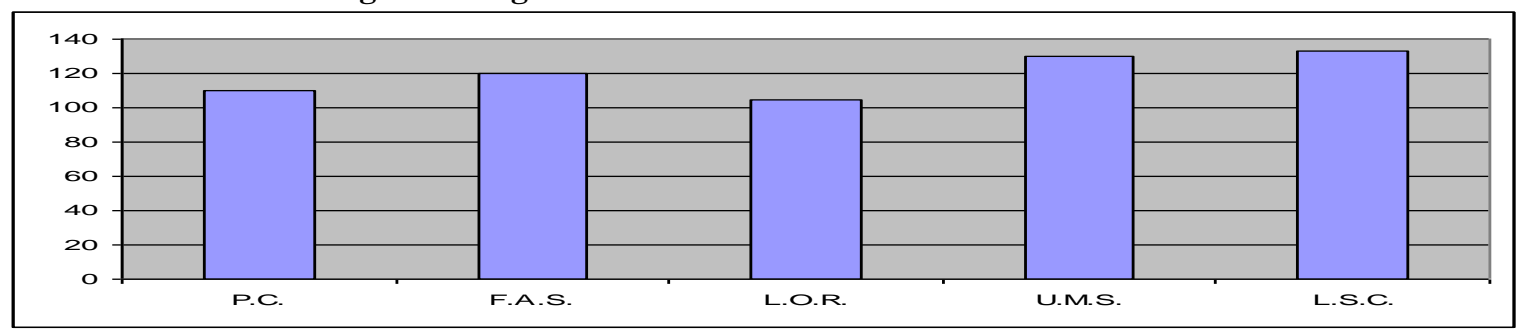

Chart 4.1 given above shows the responses of 133 respondents on the questions about the factors that hamper the process of knowledge use among English language teachers. 110 respondents out of 133 agreed that prescriptive curriculum (P.C.) is an obstacle for teachers in using their knowledge among their students. As far as faulty assessment system (F.A.S.) is concerned, 120 out of 133 respondents considered it an impediment in knowledge use. Lack of resources (L.O.R.) has been taken as a barrier in knowledge use by 105 out of 133 respondents. Unmotivated students (U.M.S.) themselves are a barrier for teachers in using knowledge, this is supported by 130 out 133 respondents. All 133 respondents agreed that large size classes (L.S.C.) are a hindrance for teachers to use their knowledge. All variables are given below according to the response of the respondents.

Variable

Large Size Classes

Unmotivated Students

Response \& Percentage

(Agreed by all 133 respondents \& $100 \%$ )

Faulty Assessment System

(Agreed by 130 out of 133 respondents \& 97.74\%)

(Agreed by 120 out of 133 respondents \& 90.22\%)

Prescriptive Curriculum

(Agreed by 110 out of 133 respondents \& $82.70 \%$ )

Lack of Resources

(Agreed by 105 out of 133 respondents \& 78.94\%)

\section{See the illustration below for the quick understanding of the factors impeding knowledge use.}

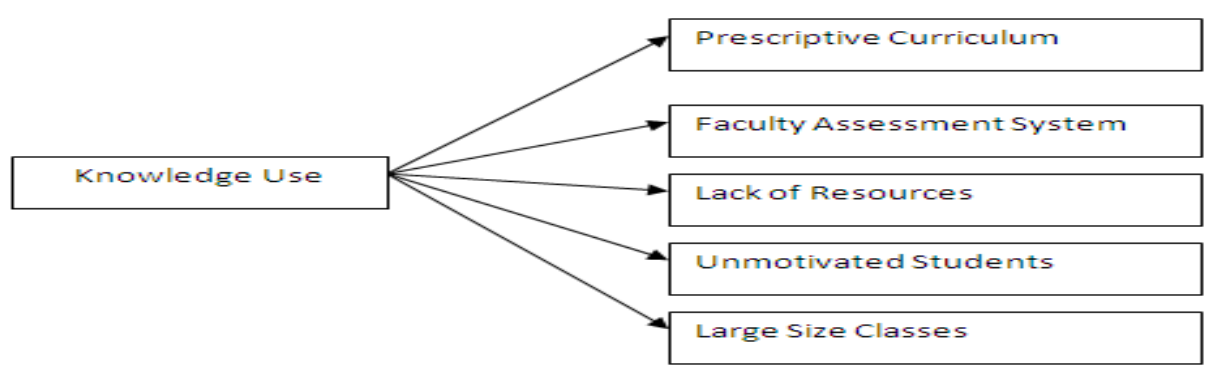

Discussion on Hypotheses (1-2)

H.1. Less equipped classrooms due to lack of resources, unmotivated students and faulty assessment system hinder the process of knowledge use.

H. 2. Large-size classes and prescriptive curriculum obstruct the process of knowledge use.

Hypotheses one and two about knowledge use were taken by the researchers before starting this study. Hypotheses need no longer discussion here. Data interpreted above clearly proves these hypotheses. 


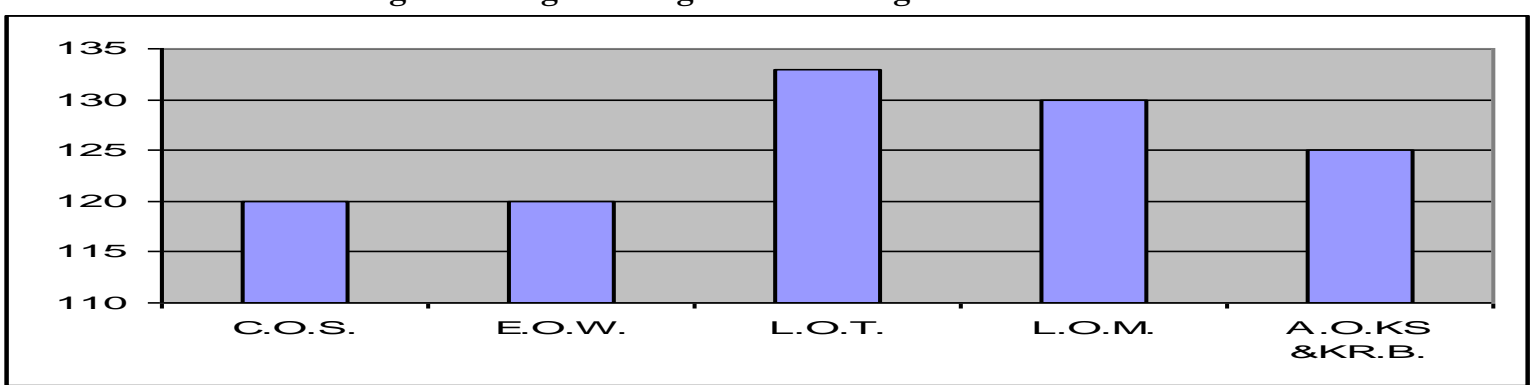

Chart 4.2 given above shows the responses of 133 respondents on the questions about the factors that hamper the process of knowledge sharing and knowledge creation among English language teachers.120 respondents out of 133 agreed that centralized organizational structure (C.O.S.) is an obstacle for teachers in sharing and creating knowledge in organizations. As far as excess of work (E.O.W.) is concerned, 120 out of 133 respondents considered it an impediment in knowledge sharing and creation. Lack of trust (L.O.T.) has been taken as a barrier in knowledge sharing and creation by 133 out of 133 respondents. Lack of motivation ( L.O..M.) is a barrier for teachers in sharing and creating knowledge, this is supported by 130 out 133 respondents. 125 out of 133 respondents agreed that the absence of knowledge sharing and knowledge receiving behavior (A.O.KS \& KR.B.) is a hindrance for teachers to share and create knowledge. All variables are given below according to the response of the respondents.

Variable

Lack of Trust

Lack of Motivation

Absence of KS \& KR Behavior

Centralized organizational structure

Excess of work
Response \& Percentage

(Agreed by all 133 respondents \& 100\%)

(Agreed by 130 out of 133 respondents \& 97.74\%)

(Agreed by 125 out of 133 respondents \& 93.98\%)

(Agreed by 120 out of 133 respondents \& 90.22\%)

(Agreed by 120 out of 133 respondents \& 90.22\%)

See the model below for the vivid understanding of the factors obstructing knowledge sharing and knowledge creation.

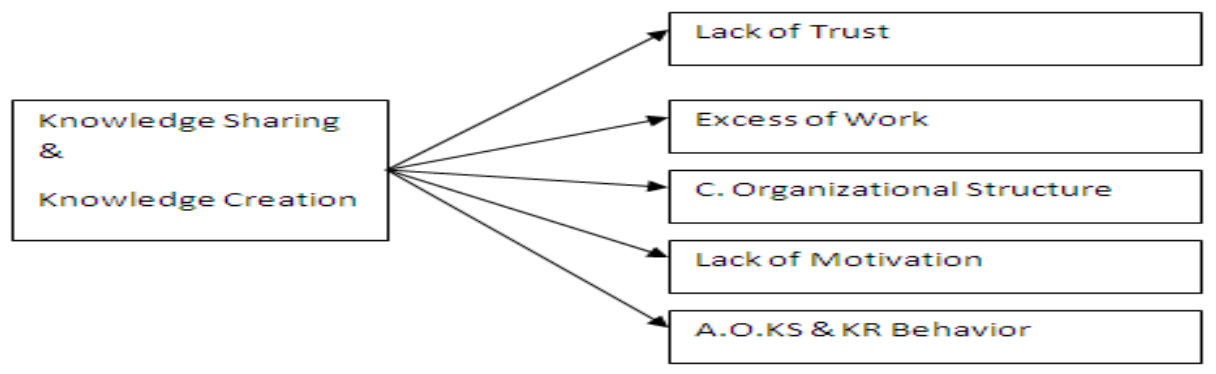

\section{Discussion on Hypotheses (3-5)}

H. 3. Lack of motivation and lack of trust among English language teachers impede knowledge sharing and knowledge creation.

H. 4. Absence of socialization due to excess of work and centralized structure of the organization are obstacles in knowledge sharing and knowledge creation.

H. 5. Lack of knowledge sharing and knowledge receiving behavior among English teachers is also a barrier in knowledge sharing and knowledge creation.

Hypotheses 3-5 about knowledge sharing and creation were taken by the researchers before starting this study. Hypotheses need no longer discussion here. Data interpreted above clearly proves these hypotheses.

\section{Conclusions And Recommendations}

Findings of this study reveal that the factors like large-size classes, lack of resources, prescriptive curriculum, unmotivated students and the faulty assessment system create impediments for the teachers in knowledge use. These are the issues to be addressed. Teachers cannot use their full potential in using knowledge.

Findings also support that the problems like centralized organizational structure, excess of work, lack of trust, lack of motivation and an absence of knowledge sharing and knowledge receiving behavior among teachers hinder the process of knowledge sharing and knowledge creation. These are the constraints for the teachers in sharing and creating knowledge. To ensure knowledge sharing, knowledge creation and knowledge use, the following recommendations can be given. 
- Curriculum and assessment system must be revised so that the teachers may be able to use their knowledge effectively without any constraint.

- Classrooms should be equipped enough to use multimedia for effective teaching. Classrooms should also be comfortable enough both for the student and the teacher to feel ease while being in the room. Moreover classes should not be so large in which teacher may confront difficulties to impart knowledge.

- If the motivation level of the students is increased, both teaching and learning will be effective.

- Educational organizations should make their structure de-centralized so that the teachers may share knowledge and create knowledge.

- Educational organizations should discourage the excess of work so that the teachers may have time to share knowledge.

- Educational organizations should promote the trust and increase the motivation among the teachers to enable them to share and create knowledge.

- It is the responsibility of both the teachers and the organizations to promote knowledge sharing and knowledge receiving behavior.

- Government of Pakistan should take some immediate measures to improve the faulty assessment and prescriptive curriculum should also be revised.

In short, it is essential to implement the above mentioned recommendations. With the help of above stated strategies, the educational organizations can sustain their academic excellence for a long time. Many researchers have conducted researches on knowledge management practices but in relation with business firms and companies. The Researchers feel that it is an innovative and significant study to research knowledge management practices and methods in perspective of educational organizations.

\section{References:}

[1] Al-Otaibi G. Language learning strategy use among Saudi EFL students and its relationship to language proficiency lever, gender and motivation [PhD Dissertation]. Indiana (PA): Indiana University of Pennsylvania 2004

[2] Abrams, L.C., Cross, R., Lesser, E., \& Levin, D.Z. (2003). Nurturing interpersonal trust in

[3] knowledge-sharing networks. Academy of Management Executive, 17(4), 64-77.

[4] Block D. \& Cameron D. (eds.) (2002). Globalization and Language Teaching. Oxford: Routledge. Bonner, D. (2000b), “The knowledge management

[5] challenge: new roles and responsibilities for chief knowledge officers and chief learning officers', in Phillips, J.J. and Bonner, D. (Eds), Leading Knowledge Management and Learning, American Society for Training \& Development, Alexandria, VA,pp. 3-19.

[6] Burgess, T. , Fox, C. , \& Goody, J. (2002). When the Hurly Burly's Done: What's Worth Fighting for in English in Education. Sheffield: National Association for Teaching of English.

[7] Crystal. D.(2002). Emerging English. English Language Professional. 14,3 -.6.

[8] Damanpour, F. (1991), Organizational innovation: a meta-analysis of effects of determinants andmoderators. Academic Management Journal, 34(3), 555-9

[9] Fisher, R.(2004). Embedding the literacy strategy: snapshots of change. Literacy, 38(3), 134-140

[10] Hanke, V. (2002). Improvisations around the National Literacy Strategy. Reading Literacy and Language, $36(2), 80-7$.

[11] Hansen, M.T., Nohria, N. and Tierney, T. (1999), “What's your strategy for managing knowledge?', Harvard Business Review, March-April, pp. 106-16.

[12] Heller, M. (2005) Linguistic Minorities and Modernity: A sociolinguistic Ethnography. London: Longman.

[13] Jiacheng, W., Lu, L., \& Francesco, C. A. (2010). A cognitive model of intra-organizational knowledge-sharing motivations in the view of cross-culture, International Journal of Information Management, 30, 220-230.

[14] Lin, C.P. (2007). To share or not to share: Modeling tacit knowledge sharing, its mediators and antecedents. Journal of Business Ethics, 70, 411-428

[15] Liss, K. (1999), “Do we know how to do that? Understanding knowledge management', Harvard Management Update, February, pp. 1-4.

[16] Nonaka, I. (1994). A dynamic theory of organizational knowledge creation. Organization Science,5(1), 14-37. Scholte. J.A. (2001). "The Globalization of world politics" in The Globalization of World politics.(eds). By Baylis.J. \& Smith.S. Oxford:Oxford University Press. Smith, L. (2008). "English as an International Auxiliary Language" RELC Journal 7/2. Siddiqui, S.(2007). Rethinking Education in Pakistan: Perceptions, Practices, and Possibilities. Lahore: Paramount Publishing Press.

[17] Sternberg, R.J. (1997), Successful Intelligence, Penguin Putnam, New York, NY.

[18] Szulanski, G. (1996). Exploring internal stickiness: impediments to the transfer of best practice

[19] within the firm. Strategic Management Journal., 17, 27-43.

[20] Tsai, W. (2002). Social structure of "cooperation" within a multiunit organization: coordination, competition, and intraorganizational knowledge sharing. Organizational Science,13(2),179-90.

[21] Tsai, W. (2000). Social capital., strategic relatedness and the formation of intra-organisational linkages. Strategic Management Journal., 21(9), 925-939.

[22] Tsai, W., \& Ghoshal., S. (1998), Social capital and value creation: the role of intrafirm networks.Academy of Management Journal., 41(4), 464-476. 